\title{
Thyroid Gland Abscess: Uncommon complication
}

Ikrame Boumendil $^{1}$, Hajar ait taleb ${ }^{1}$, Hanaa Rahim ${ }^{1}$, Sophia Nitassi ${ }^{2}$, Abdelilah Oujilal², Leila Essakalli²

${ }^{1}$ Resident physician at the department of otorhinolaryngology and head and neck surgery, Ibn Sina university hospital, Mohamed V University, Rabat, Morocco.

${ }^{2}$ Professor at the department of otorhinolaryngology and head and neck surgery, Ibn Sina university hospital, Mohamed V University, Rabat, Morocco.

*Corresponding author: Ikrame Boumendil, Resident physician at the department of otorhinolaryngology and head and neck surgery, Ibn Sina university hospital, Mohamed V University, Rabat, Morocco.

Received Date: May 19, 2021; Accepted Date: June 04, 2021; Published Date: June 09, 2021

Citation: I Boumendil, Hajar a taleb, H Rahim, S Nitassi, A Oujilal, et al. (2021) Thyroid Gland Abscess: Uncommon complication. Journal of Endocrinology and Disorders. 5(3): Doi: 10.31579/2640-1045/075

Copyright: (C) 2021 Ikrame Boumendil. This is an open-access article distributed under the terms of the Creative Commons Attribution License, which permits unrestricted use, distribution, and reproduction in any medium, provided the original author and source are credited.

\section{Abstract: \\ The thyroid gland is naturally resistant to infectious processes, which explains the rarity of thyroid abscess. It represent about $0.1 \%$ of the surgical thyroid pathology. We report in this article a case of thyroid gland abscess in a 61 year-old man who was followed for diabetes and hypothyroidism with poor adherence, who consulted in emergency department for acute neck swelling. CT scan showed a fluid collection of the left thyroid lobe. The patient was operated, and histopathological examination concluded of laryngeal carcinoma associated to thyroid papillary carcinoma.}

Keywords: thyroid abscess; laryngeal carcinoma; imaging; surgery

\section{Introduction:}

The thyroid gland is essentially protected from being seeded by infections due to its anatomy. It is surrounded by a capsule, and it has excellent blood supply and lymphatic drainage. The iodine content of the gland also prevents infections [1]. Even among those with impaired immune systems, thyroid abscesses are rare complications of neck infection and suppurative thyroiditis with incidence being less than $1 \%$ of all thyroid diseases. It is most commonly caused by gram-positive aerobes, (Staphylococcus aureus), but there are also reports of gram-negative organisms and fungi [2]. Treatment is intravenous antibiotic therapy with drainage and/or thyroid surgery. If untreated it could be fatal [3].

The aim of our study is to report a case of a thyroid abscess, discuss diagnostic circumstances, clinic and therapeutic involvement of this disease.

\section{Case report:}

It is about a 61 year-old man, with a history of 25 pack/year active smoking, who had no underlying thyroid pathology. The patient was presenting a dysphonia associated at inspiratory effort dyspnea for eight months. He consulted in emergency department for acute neck pain and swelling that progress into difficulty swallowing and breathing developed the last five days.
On physical examination, she was noted to be afebrile, tachycardia into 120 s, dyspneic. He had a painful, tender anterior neck swelling with inflammatory signs. There were no palpable lymph-nodes.

He was admitted with a suspected infection or malignancy. Fiberscope examination and cervical-thoracic computed tomography were performed and objectified a process of the left vocal cord extended to the three laryngeal stages and invading the left thyroid lobe, the seat of an abscess measuring $6 \mathrm{~cm}$ (Fig1).

The blood biochemical investigations revealed: leukocytes $21.13 \times 10^{3} / \mathrm{ul}$, CRP 190mg/L, ESR $50 \mathrm{~mm} / \mathrm{h}$, TSH $0.028 \mathrm{mIU} / \mathrm{L}$, T4 thyroxine (T4) 1.77 $\mathrm{ng} / \mathrm{dl}$ and free tri-iodothyronine (T3) $2.08 \mathrm{ng} / \mathrm{dl}$. Antithyroperoxidase antibodies and thyroglobulin antibodies were negative.

The needle aspiration returned $30 \mathrm{ml}$ of yellowish purulent fluid and bacteriological examination having isolated Klebsiella pneumonae.

After a week of intravenous bi-antibiotic therapy, the patient underwent a total laryngectomy with total thyroidectomy and bilateral neck dissection. The histopathology revealed the association of squamous cell carcinoma of the larynx with thyroid papillary carcinoma and the existence of micrometastasis of papillary carcinoma. Radio-chemotherapy combined with iratherapy has been indicated.

The 8-month follow-up was marked by the absence of any local or distant recurrence. 


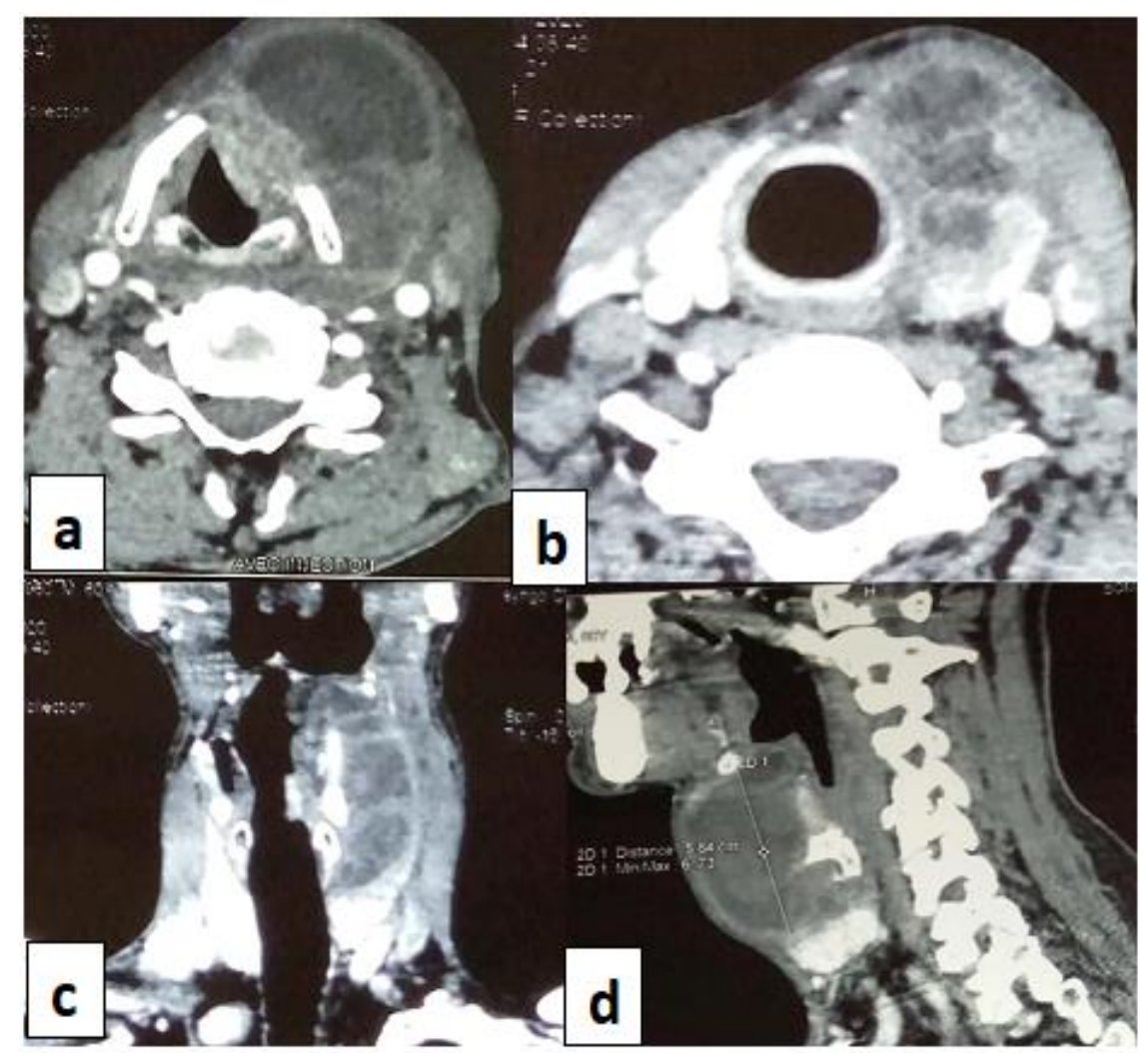

Figure 1: Images of computed tomography of the neck with contrast: axial (a, b), coronal (b) and sagittal (d) reconstructions demonstrate a process of the left hemi-larynx with a mass of fluid density, heterogeneous, containing fine partitions, enhancing after contrast injection, measuring $58 * 46 * 58 \mathrm{~mm}$, depending on the left lobe of the thyroid.

\section{Discussion:}

Acute infection of the thyroid is a less seen diagnosis, mostly so as the gland is inherently protected. The encapsulation, rich blood and lymphatic supply, and iodine content inside offer the gland protection from being seeded [1].

Thyroid abscess affects children more than adults. In children, the existence of congenital malformations such as thyroid tract fistulas, and 4 th endobrachial cleft fistula may predispose to this infection. Whereas in adults, a compromised immune state, especially acquired immunodeficiency syndrome (AIDS), can do the same. History of previous thyroid disease is another risk factor. Infection can occur also from direct extension in the neck region or from inoculation due to direct trauma - either iatrogenically, in the case of fine-needle aspiration, or from penetration through the oesophagus or skin [2]. In our patient, the existence of laryngeal and thyroidien carcinoma was the predisposing factors for this rare pathology.

Major pathogens are Staphylococcus and Streptococcus species about $35 \%$ to $40 \%$ of the time. Gram-negative organisms cause about $25 \%$ cases and anaerobes around $9 \%$ to $12 \%$, the rest being fungal etiologies. Mycobacterial and fungal cases tend to be more common in immunocompromised patients and are chronic in nature, while bacterial are more acute. In our case, the bacteriological exam isolated a klebsiella pneumonae [4].

The clinical manifestation of thyroid abscess occurs as a painful cervical swelling often following a high or pharyngeal respiratory infection. Associated signs are represented by the appearance of dyspnea, hoarseness, or even dysphonia, dysphagia, and fever .Rare presentations have been reported: vocal cord paralysis, pulsatile cervical mass or asymptomatic cases [5].

Early diagnosis is important as the disease can progress rapidly and may prove fatal. Ultrasound is the preferred imaging technique for diagnosis of thyroid diseases. It also offers the advantage of needle aspiration. Unless inconclusive, one need not obtain a CT scan or magnetic resonance imaging. If an iodine scan is done, abscess areas may appear as cold [6, 4].

The therapeutic strategy is based on probabilistic antibiotic therapy adapted to the results of the antibiogram. Surgical drainage is indicated whenever there is an objectified purulent collection at needle puncture; without waiting for signs of suffering from neighbouring structures: recurrent nerve, oesophagus or larynx. Some authors advocate an excision of the thyroid lobe seat of abscess, or at least debridement and excision of necrotic tissues, with resection of fistulas connections if possible [7].

Untreated, the abscess of the thyroid can have unpleasant consequences on neighboring organs. It can result in the destruction of thyroid glandular and parathyroid parenchyma, thrombophlebitis of the jugular vein, oesophagus, tracheal or cutaneous fistulisation, even sepsis and blood dissemination to distant organs $[3,7]$.

In our case the association of a laryngeal carcinoma to thyroid abscess imposed a surgical treatment.

\section{Conclusion:}

Although these are infrequent conditions, thyroid abscess appears to be gradually rising with the increase of immunosuppressive circumstances. Symptoms are nonspecific and are often combined with the progression of extra-glandular infection and suppuration. Imaging studies play an 
essential role in their identification, with suspicion of congenital anomalies in young people. The mainstay of this affection management is antibiotic therapy, drainage and in selected cases surgery. The treatment should be started as soon as possible to avoid complications.

\section{References:}

1. Berger SA, Zonszein J, Villamena P, Mittman N. (1983) Infectious disease of the have defects in host resistance due to diabetes mellitus, cirrhosis, thyroid gland. Rev Infect Dis.

2. Paes JE, Burman KD, Cohen J, and al. (2010) Acute bacterial suppurative thyroiditis: a clinical review and expert opinion. Thyroid.20:247-255

3. Jacobs A, Gros DA, Gradon JD. (2003) Thyroid abscess due to Acinetobacter calcoaceticus: case report and review of the causes of and current management strategies for thyroid abscesses. South Med J. 96 (3):300-307.

4. Yedla N, Pirela D, Manzano A, and al. (2018) Thyroid abscess: Challenges in diagnosis and management. J Investig Med High Impact Case Rep.

5. Gan Y, Lam SL. (2004) Imaging findings in acute neck infection due to pyriform sinus fistula. Ann Acad Med Singapore. (33):636640.

6. Naik KS, Bury RF. (1998) Imaging the thyroid. Clin Radiol.53:630-639

7. Herndon MD, Christie DB, Ayoub MM, Duggan AD. (2007) Thyroid abscess: case report and review of the literature. Am Surg. 73(7):725-728.
This work is licensed under Creative Commons Attribution 4.0 License

To Submit Your Article Click Here: Submit Manuscript

DOI: $10.31579 / 2692-9759 / 075$
Ready to submit your research? Choose Auctores and benefit from:

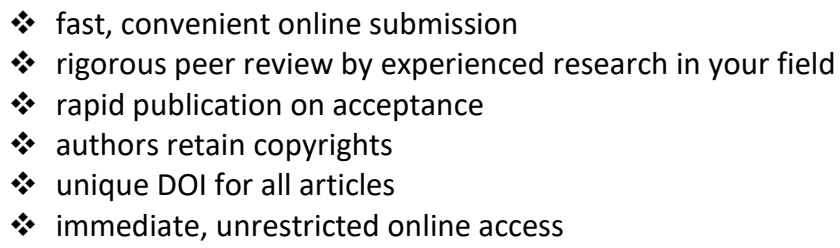

At Auctores, research is always in progress.

Learn more www.auctoresonline.org/journals/endocrinology-anddisorders 